\title{
Pulse Oximetry and Skin Temperature Gradient as Diagnostic Tools of Successful Caudal Block
}

\author{
Departments of *Anesthesiology and Pain Medicine, ${ }^{\dagger}$ Surgery, Konkuk University School of Medicine, Seoul, Korea \\ Duk-kyung Kim, M.D.*, Kyoung-Min Lee, M.D.*, Won-Kyoung Kwon, M.D.*, \\ Chung-Sik Oh, M.D.*, and Sung-Whan Jang, M.D. ${ }^{\dagger}$
}

\begin{abstract}
Background: Though caudal block is a relative simple technique, it has not been widely used in adults because of a high failure rate. We assumed that any tests to quantify the changes of sympathetic tone in the affected areas would be excellent indicators of successful block. We tested the usefulness of two candidates (pulse oximetry plethysmographic waveform amplitude measured at $5^{\text {th }}$ toe and calf minus $5^{\text {th }}$ toe skin temperature gradient) as indicators of successful caudal block.

Methods: In 45 adult patients undergoing anal surgery with caudal block, these two variables were simultaneously measured at 2-min intervals for $20 \mathrm{~min}$. A two-fold increase in the plethysmographic waveform amplitude from baseline and skin temperature gradient of $0^{\circ} \mathrm{C}$ were predefined as test criteria of successful block.

Results: While the sensitivity, specificity, positive predictive value, and negative predictive value of the skin temperature gradient test were $45.9 \%, 100 \%, 100 \%$, and $9.1 \%$, those of the plethysmographic waveform test were $86.5 \%, 100 \%, 100 \%$, and 28.6\%. The plethysmographic waveform test showed a significantly higher discriminative capacity than the skin temperature gradient test $(94.9 \%$ vs. $48.7 \%, \mathrm{P}<0.05)$

Conclusions: Unlike the skin temperature gradient test, the plethysmographic waveform test showed a considerably high validity in detecting successful block. Considering its simple and real time monitoring potentials together with a high failure rate of caudal block in adults, we cautiously recommend it as a supplemental diagnostic tool to predict successful block, especially when verbal communication with patient is difficult. (Korean J Anesthesiol 2007; 53: S 19 25)
\end{abstract}

Key Words: caudal block, pulse oximetry, skin temperature.

\section{INTRODUCTION}

Caudal block is widely used to provide perioperative analgesia in pediatric practice. However, it has only a limited application for some benign anal surgery in adults, because its success rate is only $70-80 \%$ in this population. ${ }^{1,2)}$ So, the vast majority of anal surgery in adult has been performed under spinal anesthesia, general anesthesia, or local anesthesia paired with deep intravenous sedation. Considering that $90 \%$ of anorectal surgery can be carried out on ambulatory basis, ${ }^{3)}$ there are some apparent advantages of caudal block over other techniques-the capability of selective sensory block in the anal

Received : August 2, 2007

Corresponding to : Duk-kyung Kim, Department of Anesthesiology and Pain Medicine, Konkuk University School of Medicine, 1, Hwayangdong, Gwangjin-gu, Seoul 143-701, Korea. Tel: 82-2-2030-5452, Fax: 82-2-2030-5412, E-mail: dikei@kuh.ac.kr area with sparing of motor block in legs, thereby leading to fast discharge home and the reduced risk of complications related to dural puncture and respiratory complications.

The most frequently used technique to identify the caudal space is based on feeling the 'pop' on penetrating the sacrococcygeal membrane, after the determination of the sacral hiatus by palpating the sacral cornu. In addition to this tactile feeling, the lack of resistance on injection of local anesthetic and the lack of subcutaneous swelling after injection are all subjective endpoints and operator-dependent. Even if these clinical impressions are all positive, unrecognized incorrect caudal drug administrations are observed in some cases. Additionally, pinprick and alcohol swab test, traditionally used as novel diagnostic tests, have a major limitation of the need of direct communications with patients and thus may be difficult in some situations. Even if ensuring correct communications with patients, it takes a considerably long time to confirm the success of caudal block. As sympathetic nerve fibers are 
usually the first ones to be blocked during epidural anesthesia, we assumed that any test to quantify the changes in the magnitude of sympathectomy would be an early indicator of successful block. These clinical situations prompted us to investigate simple, non-invasive, and objective tests for predicting successful caudal block. So, we planned to test the usefulness of two candidates - pulse oximetry plethysmographic (POP) waveform amplitude and calf minus toe skin temperature gradient.

POP waveform amplitude was found to be as a strong correlation with the dynamic changes of digital blood flow as laser Doppler measurements or thermography. ${ }^{4)}$ So, its variation has been used as a qualitative indicator of the peripheral circulation in a variety of clinical situations. ${ }^{5-8)}$ Considering together with a widespread availability of the pulse oximeter in the operating room, it seems to be particularly attractive. Calf minus toe skin temperature gradient is also known to be well correlated with the digital blood flow and less affected by ambient temperature than toe skin temperature alone.9) Therefore, this observational study was carried out to assess the validity of both tests in predicting successful caudal block. In addition, we investigated whether these two tests could detect onset of caudal block earlier than both alcohol swab and pinprick test.

\section{MATERIALS AND METHODS}

After obtaining approval from the institutional review board and written informed consent, 45 ASA physical status I-II patients of either sex between ages of 20-55 years undergoing benign anal surgery were included in the study. Patients were excluded if they had contraindication to regional technique, a history of medications affecting the cardiovascular system, or a history of diabetes mellitus, or peripheral vascular disease.

Patients were not premedicated. All blocks were done by one anesthesiologist with experience in performing over 200 previous caudal blocks. Lactated Ringer's solution $5 \mathrm{ml} / \mathrm{kg}$ was infused before the evaluation period. After Jack-knife positioning on the operation table, a pulse oximeter probe (Oxytip+ wrap reusable sensor, Datex-Ohmeda, Helsinki, Finland) was attached to the $5^{\text {th }}$ toe and two thermistor probes (skin temperature probe 16,560, Datex-Ohmeda, Helsinki, Finland) were attached to the calf halfway between the knee and ankle and to the plantar side of $5^{\text {th }}$ toe of the contralateral lower limb.
Selection of each monitoring side was randomized. Patients were also monitored with electrocardiography and noninvasive blood pressure monitoring every $2 \mathrm{~min}$ throughout the study.

After a 10-min stabilizing period, baseline variables were obtained. The plethysmographic signals were recorded and printed with a 10-sec length at 2-min intervals for $20 \mathrm{~min}$. During the study, the gain of the plethysmographic waveform signal remained unchanged, as the Datex-Ohmeda AS/5 monitor enables a choice between manual and automatic gain control. $5^{\text {th }}$ toe and calf skin temperatures were simultaneously measured continuously. Skin temperature gradients as well as these skin temperatures were recorded at 2-min intervals for the same observation period.

The standard single shot technique was performed in the Jack-knife position at the sacral hiatus. Under full aseptic conditions, a 22 G Tuohy needle was inserted into the caudal space using loss of resistance to air. After the negative aspiration for blood or cerebrospinal fluid, $3 \mathrm{ml}$ of $2 \%$ lidocaine with $1: 200,000$ epinephrine was injected as a test dose to detect intravascular or subarachnoid misplacement. After $3 \mathrm{~min}$, if intravenous or intrathecal misplacement of the needle had been excluded, $2 \%$ lidocaine with sodium bicarbonate $18-20$ $\mathrm{ml}$ in a fixed ratio of lidocaine $1 \mathrm{ml}$ to sodium bicarbonate $0.1 \mathrm{mEq}$ was administered $(<170 \mathrm{~cm} ; 18 \mathrm{ml}:>170 \mathrm{~cm}$; $20 \mathrm{ml}$, respectively).

Both pinprick and alcohol swab test on the skin surface innervated by the first sacral dermatome (S1) were performed bilaterally at 2-min intervals after administration of the caudal drug mixture. Bilateral loss of pinprick sensations up to S1 dermatome was defined as successful block. If the height of sensory block was below S1 after the 20-min study period, the patient was considered as failed block and then underwent surgery under local anesthesia paired with deep intravenous sedation.

All waveforms were calculated by other anesthesiologist who did not know success or failure of blocks, with using paper records obtained from the Datex-Ohmeda Aestiva/5 recorder (Aestiva/5, Datex-Ohmeda, Helsinki, Finland). The plethysmographic waveform amplitude was measured as the vertical distance between the curve base and apex of curve with the help of calipers and expressed as a ratio of baseline amplitude height. The average values of the first 5 readings of POP waveform amplitude at each evaluation interval were obtained for analysis. A two-fold increase in POP waveform amplitude from baseline was defined as a test criterion of successful 
block. Skin temperature gradient of $0^{\circ} \mathrm{C}$ was also defined as a test criterion of successful block.

Statistical analyses were performed with SPSS 12.0 for windows (SPSS Inc., Chicago, IL, USA). All data were presented as mean \pm standard deviation (SD). A two-way analysis of variance for repeated-measures was used to analyze hemodynamic changes over time. Continuous variables such as onset times of the tests were analyzed using paired two-tailed t-tests. Sensitivity, specificity, positive predictive value, and negative predictive value of both tests were calculated. $95 \%$ confidence interval (CI) was used to estimate the proportion of successful caudal blocks. For the comparison of the discriminative capacities of two tests, McNemar's test was used. Significance was defined as $\mathrm{P}<0.05$.

Table 1. Patient Characteristics

\begin{tabular}{lc}
\hline Sex $(\mathrm{F} / \mathrm{M})$ & $15 / 24$ \\
Age $(\mathrm{yr})$ & $34.1 \pm 12.1$ \\
ASA grade $(\mathrm{I} / \mathrm{II})$ & $33 / 6$ \\
Weight $(\mathrm{kg})$ & $60.5 \pm 9.8$ \\
Height $(\mathrm{cm})$ & $165.8 \pm 9.7$ \\
BMI $\left(\mathrm{kg} / \mathrm{m}^{2}\right)$ & $21.7 \pm 2.7$ \\
Initial $5^{\text {th }}$ toe skin temperature $\left({ }^{\circ} \mathrm{C}\right)$ & $26.3 \pm 1.6$ \\
Initial calf skin temperature $\left({ }^{\circ} \mathrm{C}\right)$ & $30.8 \pm 1.0$ \\
Initial calf-toe skin temperature gradient $\left({ }^{\circ} \mathrm{C}\right)$ & $4.6 \pm 1.4$ \\
\hline
\end{tabular}

Values are expressed as mean \pm SD or number of patients. ASA: American Society of Anesthesiologists, BMI: body mass index.

\section{RESULTS}

Three patients were screened by our exclusion criteria and 45 patients were included to the study. The demographic data are given in Table 1. Caudal block was successful in 37 of 45 patients. Of 8 patients who failed to develop an adequate block, six because of impossible identification of the caudal space and two because of unrecognized incorrect drug administration despite of the operator's clinical impressions of a successful placement. So, 39 patients were finally included the analysis.

In 39 patients who were actually administrated local anesthetics, the changes of heart rate and systolic and diastolic blood pressure were not significant during the study period (Fig. 1). Of 37 patients who had a successful block, the range of sensory block height was $\mathrm{S}_{1}-\mathrm{L}_{4}$ segment on both sides and unilateral or patchy block was not observed.

While the sensitivity, specificity, positive predictive value, and negative predictive value of the skin temperature gradient test were calculated as $45.9 \%$ (95\% CI: $29-63 \%), \quad 100 \%$ (95\% CI: $15-100 \%), 100 \%$ (95\% CI: $80-100 \%$ ), and $9.1 \%$ (95\% CI: 1-29\%), those of the plethysmographic waveform test were calculated as $86.5 \%(95 \%$ CI: $71-95 \%), \quad 100 \%$ (95\% CI: $15-100 \%), 100 \%$ (95\% CI: $89-100 \%$ ), and $28.6 \%$ (95\% CI: $3-70 \%$ ) (Table 2). Table 3 showed that $94.9 \%$ of patients who were tested with the plethysmographic waveform test had a correct test, compared with $48.7 \%$ of those with the


Fig. 1. Changes in heart rate, systolic blood pressure (SBP), and diastolic blood pressure (DBP) in the patients who were actually administrated caudal anesthetics $(\mathrm{n}=39)$. The changes of these hemodynamic variables during 20-min study period were not significant. Values are mean $\pm \mathrm{SD}$. Induction of the caudal block is identified as an elapsed time 0 . bpm: beats per min. 
Table 2. Comparison of the Plethysmographic Waveform Test with the Skin Temperature Gradient Test $(\mathrm{n}=39)$

\begin{tabular}{lcccccc}
\hline & \multicolumn{2}{c}{ Plethysmographic waveform test } & & \multicolumn{2}{c}{ Skin temperature gradient test } \\
\cline { 2 - 3 } \cline { 5 - 6 } & Positive $(\%)$ & Negative $(\%)$ & & Positive $(\%)$ & Negative $(\%)$ \\
\hline Successful block n (\%) & $32(82.1 \%)$ & $5(12.8 \%)$ & & $17(43.6 \%)$ & $20(51.3 \%)$ \\
Failed block n (\%) & $0(0 \%)$ & $2(5.1 \%)$ & & $0(0 \%)$ & $2(5.1 \%)$ \\
\hline
\end{tabular}

Data are number (proportion).

Table 3. Comparison of Discriminative Capacities of the Plethysmographic Waveform Test with the Skin Temperature Gradient Test $(\mathrm{n}=39)$

\begin{tabular}{lcc}
\hline & Correct test & Incorrect test \\
\hline $\begin{array}{c}\text { Plethysmographic } \\
\text { waveform test; n }(\%)\end{array}$ & $37(94.9 \%)^{*}$ & $2(5.1 \%)$ \\
$\begin{array}{c}\text { Skin temperature } \\
\text { gradient test; } \mathrm{n}(\%)\end{array}$ & $19(48.7 \%)^{*}$ & $20(51.3 \%)$ \\
\hline
\end{tabular}

Data are number (proportion). Correct test: positive result with a successful block or a negative result with a failed block. Incorrect test: positive result with a failed block or a negative result with a successful block. ${ }^{*} \mathrm{P}<0.05$ compared with the cutaneous temperature gradient test.

skin temperature gradient test. A correct test was defined as one, which gives a positive result with a successful block or a negative result with a failed block. The plethysmographic waveform test showed a significantly higher discriminative capacity than the skin temperature gradient test $(\mathrm{P}<0.05$, Table 3).

Data from patients with a failed block were used for calculation of validity profiles, but were not included in time sequence evaluation. In the plethysmographic waveform test, the mean time to the two-fold increase from baseline amplitude was $7.9 \pm 6.3 \mathrm{~min}$ (Fig. 2). In the skin temperature gradient test, the mean time to the reversal of calf minus toe skin temperature gradient (temperature gradient $\leq 0$ ) was 10.9 $\pm 4.9 \mathrm{~min}$ (Fig. 3). Onset times of predefined criteria of two tests were significantly slower than those of both alcohol swab test $(2.3 \pm 1.1 \mathrm{~min})$ and pinprick test $(4.0 \pm 1.4 \mathrm{~min})(\mathrm{P}<$ $0.05)$.

\section{DISCUSSION}

In the present study, we tested the usefulness of two candidates (POP waveform amplitude measured at $5^{\text {th }}$ toe and calf minus $5^{\text {th }}$ toe skin temperature gradient) as indicators of suc-



Fig. 2. Changes in the mean amplitude of pulse oximetry plethysmographic (POP) waveform measured at $5^{\text {th }}$ toe in the patients with a positive result of the plethysmographic waveform test $(\mathrm{n}=$ 32). The plethysmographic waveform amplitude was expressed as a ratio to baseline amplitude height. Values are mean \pm SD. Induction of the caudal block is identified as an elapsed time 0 .

cessful caudal block. We initially hypothesized that successful caudal block resulted in a considerable increase in POP waveform amplitude of $5^{\text {th }}$ toe and a negative calf minus toe skin temperature gradient. As a result, we found the superiority of the plethysmographic waveform test over the skin temperature gradient test in predicting successful caudal block. In contrast to the poor validity profiles of the skin temperature gradient test, the plethysmographic waveform test had a considerably high sensitivity of $86.5 \%$ and a positive predictive value of $100 \%$. Particularly, we had no false positive results of this test, a highly desirable characteristic for a diagnostic test, giving a specificity of $100 \%$. As for the skin temperature gradient test, its sensitivity was so low (only 45.9\%) that it might not be eligible for a practical predictive test.

In the present study, we prospectively defined a two-fold increase from baseline in POP waveform amplitude as a test criterion of successful block. The reasons why we arbitrarily 

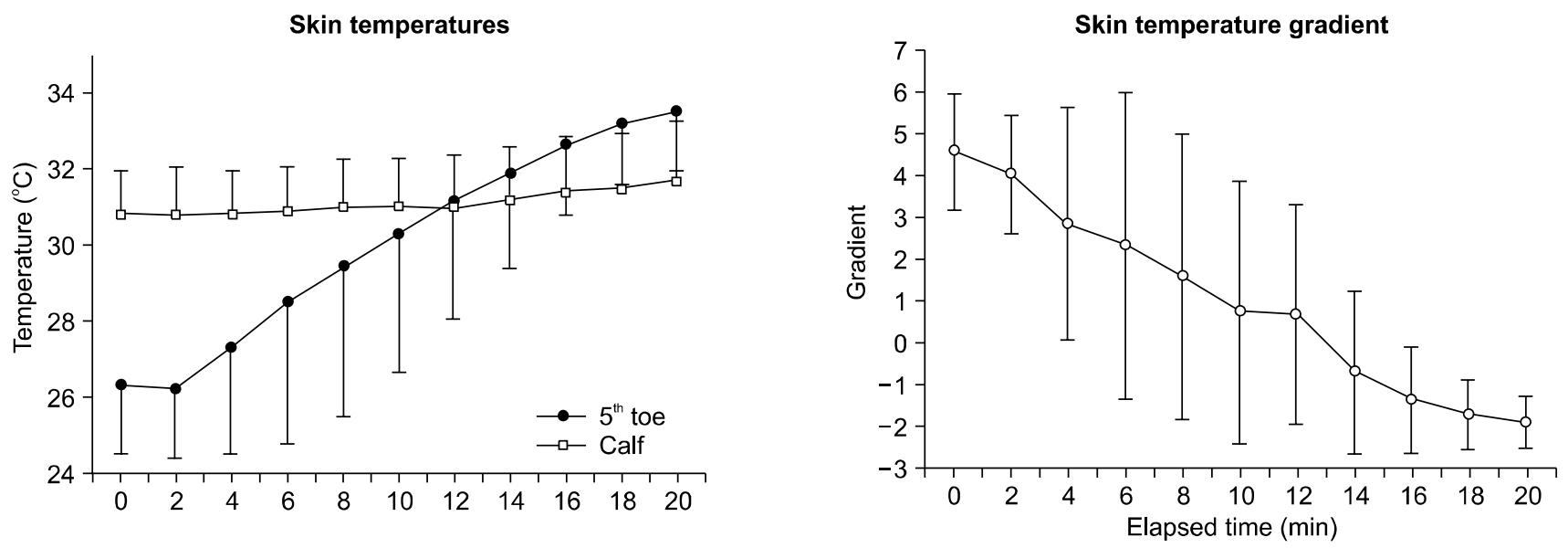

Fig. 3. Changes in the calf and $5^{\text {th }}$ toe skin temperatures and the calf minus toe skin temperature gradient in the patients with a positive result of the skin temperature gradient test $(n=17)$. Values are mean \pm SD. Induction of the caudal block is identified as an elapsed time 0 .

predetermined such a test criterion were as follows: 1) All the clinicians could easily detect such a large increase in the POP waveform amplitude on the monitor screen without additional technological supports. 2) Sinha et al. ${ }^{10)}$ had evaluated the efficacy of POP waveform variation as an indicator of successful lumbar epidural block, and had showed an amplitude increase of more than $300 \%$ of the baseline after successful blocks. And they had found that this change of POP waveform amplitude had a sensitivity of $100 \%$. 3) We did not observe POP amplitude increase to this value in the patients with a failed block in the pilot study.

In addition to oxygen saturation values, many pulse oximeters display a photoelectric plethysmographic waveform, which reflects a combination of volume and flow changes in skin microcirculation. ${ }^{11,12)}$ In this respect, the amplitude of the plethysmographic signal depends not only on systemic intravascular pulse pressure, but on local vasomotor tone. Especially, the latter is mainly regulated by sympathetic nervous system. ${ }^{5)}$ Awad et al. ${ }^{13)}$ suggested that POP waveform amplitude predominantly reflected local sympathetic tone rather than central hemodynamic changes, when the sensor was placed on the digits. Considering the small magnitude of sympathetic block in our study, the change of POP waveform amplitude was mainly attributed to the change of local sympathetic tone during caudal block.

However, in 5 of 37 patients who had a successful block, all POP waveform amplitudes remained at near-baseline values throughout the study period. Failure to demonstrate $100 \%$ validity indicates some limitation of the plethysmographic waveform test as a reliable indicator of successful caudal block. This is not in agreement with the results of Sinha et al. ${ }^{10)}$ who demonstrated that an increase in the POP waveform amplitude was reliable with a sensitivity of $100 \%$, as an indicator of successful lumbar epidural block. The major reason for this difference may be a smaller extent of sympathetic block during caudal block compared with lumbar epidural block. The other important reason may be the underlying technology of pulse oximetry. The sympathectomy that accompanies epidural (lumbar or caudal) block results in both venous and arterial vasodilation, but the venodilation effect predominates as a result of large amount of blood in the venous system (approximately $75 \%$ of total blood volume). So, vascular smooth muscle on arterial side of the circulation retains a considerable degree of local vasomotor tone after epidural block. ${ }^{14)}$ As a plethysmograph, the pulse oximeter is influenced mainly by the changes in the volume of the arterial blood, rather than venous blood. As a result, the volumetric information obtained from the pulse oximeter may have some flaw in predicting successful caudal block.

In the present study, we tested the possibility of the other clinical parameter eligible to an objective indicator for successful block - changes in calf minus $5^{\text {th }}$ toe skin temperature gradient. Our test criterion of skin temperature gradient was inferred from the study of Frank et al. ${ }^{15)}$ who found that negative calf minus toe skin temperature gradients were developed in all patients receiving lumbar epidural anesthesia and lumbar sympathetic ganglion block. Epidural anesthesia inhibits the tonic vasoconstriction that normally maintains a 
large core-to-peripheral temperature gradient. ${ }^{16)}$ As thermoregulatory arterio-venous anastomoses are abundant in the digits but virtually absent in the calf, calf minus toe skin temperature gradient may be useful in detecting thermoregulatory vasoactivity. ${ }^{17)}$

However, the skin temperature gradient test could not yield desirable results. Its low sensitivity in our study appeared to be due largely to a smaller extent of sympathetic block during caudal block. One study ${ }^{18)}$ suggested that complete blockade of vasoactivity of the lower extremities required sympathetic block more than $\mathrm{L}_{2}$ segment. Other study ${ }^{19)}$ proposed that sensory block at $\mathrm{T}_{8}$ or above was needed to produce a complete sympathetic blockade to lower extremity. But, the range of sensory block height was $\mathrm{S}_{1}-\mathrm{L}_{4}$ segment in the patients with a successful block. In epidural block, sympathetic block height is identical to sensory block height. Therefore, this low range of sympathetic block height could not induce a consistent increase of toe skin temperature. Additionally, disappointing efficacy of the skin temperature gradient test seemed to be due in part to the choice of $5^{\text {th }}$ toe skin temperature as a distal monitoring site. Werdehausen et al. ${ }^{20)}$ demonstrated that the capability of the skin to warm after regional anesthesia was predominantly determined by the abundance of subcutaneous vessels and location of arterio-venous anastomoses, irrespective of the regional anesthesia techniques. Other studies ${ }^{15,21)}$ also proposed that the most useful site for monitoring skin temperature increase during the nerve block of the lower extremity was the great toe.

The main limitation of our study design was that we did not consider the possibility of unilateral block, even if it might occur very rarely. Considering the possibility of unilateral block, whatever method is employed, it is reasonable to monitor the changes of sympathetic tone of affected areas bilaterally. Our study has some other limitations. First, our results must apply only to healthy young adults. Other patient populations, such as the elderly, those with regional vasomotor disturbances, or those receiving vasoactive drugs, may have altered plethysmographic pulse waveform and skin temperature responses, and thus require separate determination of the response criteria and the validity profiles. Second, all the commercially available pulse oximeter can not allow the choice of fixed or automatic gain control. In some pulse oximeters, the proprietary software included with these monitors generate plethysmographic signals that are substantially filtered, amplified, and smoothed automatically before they are displayed.
Any significant signal processing makes it impossible to quantify the changes of POP waveform amplitude displayed on the monitor. Lastly, onset times of the predefined criteria of both tests were significantly slower than those of both alcohol swab and pinprick tests. Though our observational study, mainly designed to show the discriminative capacities of two tests in detecting the successful caudal block, has a small sample size, it is sufficient to detect statistically significant difference of .our two tests and both novel tests with respect to the onset times. Retrospective power analysis of our data reveals that at least 12 and 8 subjects per equally-sized group are required to provide a power $>0.9(\mathrm{P}=0.05)$ for detecting statistically significant difference (50\% reduction) of onset times, compared to alcohol swab and pinprick test, respectively.

Though the above mentioned weaknesses might limit the extent of the conclusion which was drawn from the study, our attempt to develop a clinically useful indicator of successful caudal block was partly successful. Unlike the skin temperature gradient test, the plethysmographic waveform test showed a considerably high validity and discriminative capacity in detecting successful block. Further, because the POP amplitude changes during a successful block are so large, this method may be easier to use without any additional technology of pulse oximeter. Considering its simplicity and relatively satisfactory reliability together with high failure rate of caudal block in adults, we cautiously recommend it as a supplemental diagnostic tool to predict successful caudal block in the limited situation, where verbal communication with patient is difficult.

\section{REFERENCES}

1. Tsui BC, Tarkkila P, Gupta S, Kearney R: Confirmation of caudal needle placement using nerve stimulation. Anesthesiology 1999; 91: 374-8.

2. Stitz MY, Sommer HM: Accuracy of blind versus fluoroscopically guided caudal epidural injection. Spine 1999; 24: 1371-6.

3. Smith LE: Ambulatory surgery for anorectal diseases: an update. South Med J 1986; 79: 163-6.

4. Alam TA, Seifalian AM, Baker D: A review of methods currently used for assessment of in vivo endothelial function. Eur $\mathrm{J}$ Vasc Endovasc Surg 2005; 29: 269-76.

5. Mowafi HA: The efficacy of plethysmographic pulse wave amplitude as an indicator for intravascular injection of epinephrine-containing epidural test dose in anesthetized adults. Anesth Analg 2005; 101: 1506-11.

6. Bourke DL, Grayson RF: Digital nerve blocks can restore pulse oximeter signal detection. Anesth Analg 1991; 73: 815-7. 
Duk-kyung Kim, et al : Indicators of Successful Caudal Block

7. Narang VP: Utility of the pulse oximeter during cardiopulmonary resuscitation. Anesthesiology 1986; 65: 239-40.

8. Graham B, Paulus DA, Caffee HH: Pulse oximetry for vascular monitoring in upper extremity replantation surgery. J Hand Surg [Am] 1986; 11: 687-92.

9. Rubinstein EH, Sessler DI: Skin-surface temperature gradients correlate with fingertip blood flow in humans. Anesthesiology 1990; 73: 541-5.

10. Sinha PK, Dubey PK, Gaur A, Singh PK, Singh S: Plethysmographic pulse oximeter waveform variation as an indicator of successful epidural blockade: a prospective study. Anesthesiology 1999; 91: 899-901.

11. Awad AA, Stout RG, Ghobashy MA, Rezkanna HA, Silverman DG, Shelly KH: Analysis of the ear pulse oximeter waveform. J Clin Monit Comput 2006; 20: 175-84.

12. Kato R, Sato J, Iuchi T, Higuchi Y: Quantitative determination of arterial wall mechanics with pulse oximetric finger plethysmography. J Anesth 1999; 13: 197-204.

13. Awad AA, Ghobashy AM, Ouda W, Stout RG, Silverman DG, Shelley KH: Different responses of ear and finger pulse oximeter wave form to cold pressor test. Anesth Analg 2001; 92: 1483-6.

14. Brown DL: Spinal, epidural, and caudal anesthesia. In: Miller RD (Ed.). Anesthesia, 5th ed. Philadelphia: Churchill Livingstone Inc.; 2000; 1491-1519.

15. Frank SM, El-Rahmany HK, Tran KM, Vu B, Raja SN: Comparison of lower extremity cutaneous temperature changes in patients receiving lumbar sympathetic ganglion blocks versus epidural anesthesia. J Clin Anesth 2000; 12: 525-30.

16. Sessler DI: Perioperative heat balance. Anesthesiology 2000; 92 : 578-96.

17. Akata T, Kanna T, Yoshino J, Higashi M, Fukui K, Takahashi S: Reliability of fingertip skin-surface temperature and its related thermal measures as indices of peripheral perfusion in the clinical setting of the operating theatre. Anesth Intensive Care 2004; 32: 519-29.

18. Sato S, Akiyoshi $\mathrm{Y}$, Ashimura H, Nishijima $\mathrm{Y}$, Okubo N, Takahashi H: Toe skin temperature as a guide to epidural anaesthesia dosing. Can J Anaesth 1994; 41: 232-5.

19. Lundin S, Kirno K, Wallin BG, Elam M: Effects of epidural anesthesia on sympathetic nerve discharge to the skin. Acta Anaesthesiol Scand 1990; 34: 492-7.

20. Werdehausen R, Braun S, Hermanns H, Freynhagen R, Lipfert P, Stevens MF: Uniform distribution of skin-temperature increase after different regional-anesthesia techniques of the lower extremity. Reg Anesth Pain Med 2007; 32: 73-8.

21. Trans KM, Frank SM, Raja SN, El-Rahmany HK, Kim LJ, Vu B: Lumbar sympathetic block for sympathetically maintained pain: changes in cutaneous temperature and pain perception. Anesth Analg 2000; 90: 1396-401. 